\title{
Vermin, Victims and Disease: UK Framings of Badgers In and Beyond the Bovine TB Controversy
}

\author{
Angela Cassidy \\ Centre for History of Science, Technology and Medicine (CHOSTM), Imperial College London \\ e-mail: angela.cassidy@imperial.ac.uk; angela.cassidy@gmail.com
}

\begin{abstract}
The question of whether to cull wild badgers in order to control the spread of bovine TB (bTB) in UK cattle herds has been deeply contentious for nearly 40 years, and still shows no sign of resolution. This paper will examine the strategic framing of badgers in recent debates over bTB in the UK media, which take two opposing forms: the 'good badger' as epitomised in Kenneth Grahame's children's novel 'The Wind in the Willows'; and the less familiar 'bad badger': carnivore, digger, and carrier of disease. It will then uncover the deeper historical and cultural roots of these representations, to argue that underlying the contemporary 'badger/bTB' controversy is an older 'badger debate' about the proper relationship between these wild animals and humans. Finally, the implications of this finding for current debates over bTB policy will be explored.
\end{abstract}

\section{Introduction}

Since the early 1970s, the question of whether to cull wild badgers (Meles meles) in order to control the spread of bovine TB (bTB) infections in UK cattle herds has provoked an ongoing, divisive and increasingly high profile public controversy. Despite the near-eradication of the disease during the 1960s, following intensive control campaigns instituted to combat what was once a major public health threat (Waddington 2006), infection rates have since risen as it spreads across the country again (Defra 2010). While the full reasons for this resurgence remain unclear, veterinarians and farmers point to the existence of a 'reservoir' of infection in wild badger populations as the underlying source of the problem. These groups have supported policies of 'badger control' (culling), in place from the 1970s until the early 1990s; while conservation and animal welfare groups have campaigned against such policies. In 1996, senior scientist John Krebs was commissioned by the then government to review the scientific evidence of the effects of badger culling on cattle TB. After concluding that the evidence at the time was inconclusive, he argued that research systematically investigating the issue was needed before any 
effective policy could be formulated (Krebs et al. 1997). The incoming Labour government commissioned the Randomised Badger Culling Trial (RBCT), which after nearly ten year's research and a cost of about $£ 50$ million, concluded that some forms of culling appeared can actually facilitate the spread of bTB; and that 'badger culling cannot meaningfully contribute to the future control of cattle TB in Britain' (ISG 2007, p. 14). Since 2007, these conclusions have been heavily contested by, among others, animal health researchers; the government's own Chief Scientist; veterinary and farming associations; and specialist agricultural media. The UK has also seen two different government administrations adopt opposing bTB/culling policies based largely upon the same empirical evidence, with further diversity in bTB policies in the devolved regions of Wales, Scotland and Northern Ireland (Spencer 2011).

Alongside the growing body of research addressing the epidemiology, ecology, and economics of the bTB problem in the UK, a small social scientific literature on bTB has developed. This has included work on the contradictions of evidence and policy involved (Grant 2009; Spencer 2011; Wilkinson 2007); the role of scientific knowl- edge (Enticott 2001); farming (Enticott 2008, 2011a) and veterinary perspectives on bTB (Enticott et al. 2011; Enticott 2011b). However, as yet no research has addressed the roles of the media, popular culture or the broader public sphere in the badger/bTB controversy, despite their role in providing the central mediating space where actors on all sides have communicated with each other and wider 'publics'. This article presents findings from a research programme investigating public debates over badgers and bovine TB, including the role of media practices and broader political dynamics in shaping the debate. However, this paper will take a step back from bTB, to instead focus on the role of badgers. Why have proposals to cull badgers in particular provoked such intense and sustained controversy in the UK at this time?

Bovine TB can affect many mammal species (including humans), and several countries have both reservoirs of infection in wildlife and active culling policies without attracting the degree of controversy experienced in the UK (e.g. Ryan et al. 2006; More 2009). Furthermore, the European badger (including various subspecies) lives across most of temperate Eurasia, from the Iberian peninsula to Japan. Despite the existence of bTB in cattle across much of this area, it is only in the UK and the Republic of 
Ireland that direct causal links have been drawn between the two. This suggests that a highly specific combination of ecological, economic, social and cultural factors contribute to the badger/bTB situation in Britain and Ireland (Byrne et al., forthcoming; Roper 2010; ch. 7). Furthermore, it is only in the UK that culling policies have been met with such sustained and increasingly high profile opposition. The importance of local context for understanding BTB is underlined by the highly variable state of policy, protest, badger ecology and bTB epidemiology internationally, as well as locally across the devolved regions of the UK (see Spencer 2011 for a useful summary) Badgers occupy a significant position in British society, whereby they benefit from extensive legal protection and a highly visible and enthusiastic network of local support groups (the Badger Trust), yet at times continue to be subject to (illegal) human practices of badger 'baiting' (fighting for sport), 'digging' (digging out a sett and/or sending terrier-type dogs in to hunt the animals), and 'control' activities from farmers and gamekeepers (Enticott 2011a; Roper 2010, 39-41). Alongside the similarly conflicted fox (Woods 2000; Marvin 2001) and otter (Allen 2010; Syse 2010) badgers are also culturally significant in the UK, appearing in folklore, fiction, poetry and visual imagery.

The article will contribute to the field of animal studies, which addresses all aspects of relations between human and other animals, from pet-keeping and farming through to hunting and eating (e.g. Philo and Wilbert 2001). This literature has seen a particular emphasis on processes of relating with 'companion animals' (Haraway 2007; Lorimer 2010), while research on wildlife often explores direct interactions during hunting ( $O^{\prime}$ Keefe 2007). But what happens in human relationships with an animal which is rarely interacted with directly (as either 'companion' or hunted animal), yet is so prominent in popular culture? This article also draws upon research on human-animal conflict, much of which is carried out in global conservation contexts. Work by the anthropologist John Knight (2000a) and colleagues outlines some of the ways in which human characterise animals that they come into conflict with. Knight (2000b, pp. 8-11) describes these as 'pestilence discourses', which often present exaggerated claims of the damage animals do, and represent them as dirty, violent, criminal, cunning, highly numerous and out of control. While the article will focus principally on framings and representations of badgers themselves, this will be through the lens of their construction in the broader public sphere, and specifically the contested 'public arenas' of ongoing environmental conflicts (see, e.g. Lester 2010; 37-58). As 
Molloy (2011), and Corbett (2006; ch. 7) point out, animals play important roles in the development of engaging popular media content, which in turn contribute to broader public discourses and understandings of those animals.

\section{Data collection and methodology}

This article draws on a wide range of sources, providing a degree of triangulation and historical context that would be otherwise unavailable. The principle data source for this analysis has been the LexisNexis print media database, from 1995-2010, searching for 'badger' and 'TB'. This covers the most recent phase of controversy over badgers and bTB dating from the commissioning of the Krebs report in 1995. It has included only UK national newspaper titles, as it was felt that including local/regional and specialist media would require theoretical and practical resources beyond those available, particularly to do justice to regional debates such as that in Wales. ${ }^{1}$ This search produced a core sample of newspaper articles, analysed using principles drawn from grounded theory (e.g. Strauss and Corbin 1998), and the qualitative data analysis software Atlas.ti. This involved an interactive process of coding, starting with informal reading of the material and identification of the key actors in the debate. An initial coding framework was developed on paper: this was then transferred into the software and implemented, working back and forth between data, theory and coding until the framework was robust.

The core sample was then supplemented with material obtained through less formal means, including Google alerts and image searches; social media, newspaper, parliamentary and governmental websites; and viewing relevant TV and radio programmes. In order to look beyond the contemporary controversy, two further data sources have also been used. The electronic archive of The Times, which spans from 1785-1985, was searched for 'badger' and 'animal'. Finally, representations of badgers in British culture, including folklore; children's fiction; poetry; popular science; comedy; and visual images were gathered: initially through references in the media sample, and subsequently during interactions with friends, colleagues, and (most crucially) actors involved in the controversy. These latter samples were not suitable for the same style of detailed analysis used with the press/media coverage, but the same 
coding framework was applied to draw out key themes and comparisons. ${ }^{2}$ An under- standing of grounded theory as an interactive process has also informed the research design as a whole; whereby the varying stages of media and cultural data collection; quantitative and qualitative analysis; and qualitative interviewing (not drawn upon for this article) have informed each other as the research has progressed.

\section{Framings of badgers in media coverage of the contemporary bTB debate}

UK media coverage of badger/bTB has been striking in its tight focus on badgers, and the associated question of whether they should be culled. Far less attention has been paid to other potential factors in the spread of the disease such as cattle movement, or bTB testing regimes. Which issues are foregrounded (and which obscured) can draw our attention to the ways in which the problem itself has been framed by various actors. The central character in this coverage has been the figure of the badger, or perhaps more accurately, two opposing framings of the animal.

\section{'GoodBadger'}

For many people in the UK, their first encounter with a badger is likely to be via Kenneth Grahame's (1908) children's novel The Wind in the Willows (WiTW): in fact, many more people are likely to be familiar with 'Mr. Badger' from WiTW than will ever encounter the living wild animal. While it is not the only cultural source referenced in coverage of badger/bTB, WITW is by far the most prominent, and so provides a good place to start. While the book will be discussed at depth below, at present it is useful to note that 'good badgers' in media coverage often share characteristics with 'Mr. Badger', such as being mysterious/shy/averse to social contact; intelligent/wise; and a brave/strong fighter when attacked:

\section{SUPER FURRY ANIMAL OR CATTLE-KILLING, TB-RIDDEN VERMIN?}

'People don't just love them because they are cuddly, but because they are so full of mystery. You see the size of their claws, and their teeth, and how quick they are, you don't want to mess with them - I suppose that was the challenge for badger baiters'. (Adams 2008, May 4; Observer Magazine, p. 24)

When people do encounter badgers in the wild, this seems to confer an 
important sense of connection with wildlife and the natural world:

\section{IF YOU GO DOWN TO THE WOODS TODAY}

'The first time a young badger bounced down the garden to greet me, I felt a flush of pride. Presumably it had mistaken me in the dark for a fellow badger - it bolted the second it realised its error. But it was still gratifying, as if its' snuffling at my feet conferred some kind of seal of approval from the natural world'. (Askwith 2003, June 13; The Independent)

While such chance encounters are rare, this sense of connection may in part account for the popularity of 'badger watching' as a leisure activity. ${ }^{3}$ While people rarely encounter badgers by accident, due to their nocturnal lifestyle, a combination of poor eyesight, routine foraging habits, and an omnivorous diet means that given the right conditions it can be relatively easy for an amateur to seek out and observe them. ${ }^{4}$ This happens along a continuum with people feeding badgers visiting their gardens at one end, and organised holiday breaks at the other.

\section{TEA FOR TWO, PLEASE}

'Sat under a beech tree in the cow field behind the cottage and waited,' reads an entry in the visitors' book at Westley Farm in the Cotswolds. 'At about 9.20pm a large badger came across the field towards me. He came up to the tree and sniffed around the roots on which I was sitting. Wow! Then something I will never forget-he sniffed at the leg of my jeans, stopped, looked up, our eyes met'. (Ellis 2002, 6 July; The Times (Weekend) p. 6)

While initially it seems contradictory for dairy farmers (often represented as hard-pressed due to bTB) turning to people's love of badgers as an alternative income source, farming attitudes to the badger/bTB situation may be more variable than the stereotype suggests:

There is irony in the badger becoming a farm's best friend, particularly in Gloucestershire, where the incidence of bovine TB has been relatively high. 'Many farmers are terrified of TB and are anti-badger,' Julian says. 'But not the small farms in this valley'. The Usbornes believe that wider issues, such as feed, animal husbandry and cattle controls, need to be explored. Why, they ask, are some herds free of TB while others in the same area are infected? (Ellis 2002, 6 July; The Times(Weekend), p. 606)

In comparison to continental and northern European populations, badgers in the UK and Ireland are more likely to live in very large social 
groups based in setts which can be continually occupied for hundreds of years (Roper 2010). In the media, this habit is often linked to framings of badgers as animals with intimate and longstanding connections with the land, a 'native' species, therefore ancient, and symbolic of British national identity.

\begin{abstract}
LEADING ARTICLE: IN PRAISE OF ... BADGERS
'The most ancient Briton of English beasts,' wrote the poet Edward Thomas of the badger, a justified verdict on a black-and-white creature that has always added colour to the nation's life. The appearance of one sett in the Domesday Book merely marks the start of the current chapter in a tale stretching back a quarter of a million years. Despite their elusive nature, their inquisitive face is still one of the most recognisable symbols of British wildlife. (Guardian Leader 2007, May 15; The Guardian, p. 28)
\end{abstract}

This is often underlined by the use of an older, often reputed to be 'Celtic' name for the badger: 'brock', mentions of place names (e.g. Broxbourne) and attributions of age and gender: 'Mr.' or 'Old' Brock. As the above quote suggests, this national symbolism is closely connected to one of wildlife/countryside/nature. Despite their clear co-existence in human spaces (farms, gardens), 'good badgers' tended to be discussed as if they spend most of their time in the 'natural' space of the Wild Wood.

An overlapping, but distinct set of 'good badger' characteristics involves framings of badgers as social (with other badgers), family oriented, and with humanlike attributes. ${ }^{5}$

\title{
TB OR NOT TB?
}

They have young ones to feed at this time of year, ablutions to perform and family grooming duties, as well as house cleaning and repairs to do. It is a furiously hectic life below ground. In fact, on still frosty nights you can see a plume of steam lifting from an air vent built by the badgers at the back of their sett, like the warm white billows drifting upwards from sidewalks above the New York subway. And these animals are our deadly enemy? (Mitchell 2006, Mar 4; Daily Telegraph (Weekend), p. 1)

Although badgers are omnivores, whose diet includes predation on small mammals (including baby rabbits and hedgehogs), birds and eggs, 'good badger' framings tend to emphasise the more innocuous aspects of this diet such as worms, insects, snails and nuts: 


\section{BLACK AND WHITE AND BRED ALL OVER}

On a good night, badgers suck worms out of the ground just like children eat spaghetti. (Beardsall 2003, Aug 9; Daily Telegraph, p. 12)

Unsurprisingly, framings of badgers as victims (of risks from humans) have been particularly prominent in this coverage. Most directly, these reference the historical (and ongoing) role of badgers as an animal subjected to (illegal) practices of baiting and digging, as referenced in the first quotation in this section. In the UK, badgers are protected by law to a degree roughly equivalent to that enjoyed by endangered species such as raptors - up to and including protection against interference with a sett. At times, the 'badger as victim' framing places these protections and practices into a broader context of historical relations between humans and wildlife in general in the UK:

\section{STOP PICKING ON MR. BROCK: IT'S THE SILLY COW WITH TB YOU SHOULD BE BLAMING \\ Death is always the soft option - at least, it is for those not doing the actual dying. The badger cull is all of a piece with the slaughter of predators that was all the rage in the nineteenth century and still continues in some places, illegally, today. When in doubt, blame a wild creature; and then kill it. Job done. (Barnes 2006, Oct 7; The Times, p. 23)}

Finally, the badger as victim is discussed in very direct human terms, placing the reader directly into the shoes (paws?) of animals facing death from impersonal authorities. This is particularly clear in emotive newspaper headlines such as 'The Culling Fields' (Independent Leader 2005 , p. 30), or descriptions of the cull as a 'slaughter' or 'holocaust', immediately recalling the (human) Holocaust of WW2.

\section{TB OR NOT TB?}

There must be an immediate 'blitz cull' of as many as 100,000 badgers massed gassings, total elimination zones extending across swathes of Devon, Somerset, Cornwall and any other seriously affected county. No more waiting. Push the red button. Do it now. (Mitchell 2006, March 4; Daily Telegraph (Weekend), p. 1)

This 'victim' mode is underlined by depictions of badgers as female, as children, or likening their situation to that of refugees:

Mother badgers are snared in rusty cages, parted from their screaming cubs and 
coldly shot in the head ... all with the government's blessing

Trapped in a small, rusting cage this despairing badger paws at the bars and pushes her snout through the bars as she struggles to escape. Somewhere in the darkness a cub screams for its mother. (Weathers 2003, June 3; Daily Mail, p. 11)

\section{ACULLBYROYALAPPOINTMENT}

A cull - by its nature incomplete - 'would have a profound effect on the lifestyle of survivors. It might well cause changes in their immune systems which make them less resistant to disease. With their society in turmoil, bereaved badgers would almost certainly traverse the country far and wide, infecting more badgers and more cattle'. (Hattersley 2005, Dec 22; The Times, p. 18)

This set of discourses, placing the badger culling in terms of human war, and the victims of war, provides an interesting appropriation of the historical and contemporary metaphor of 'the battle against disease' (Nerlich and James 2009). Rather than utilising the bellicose language of waging war, it instead invokes anti-war rhetoric to draw attention to the consequences for badgers of 'eradicating' bTB.

\section{'Bad Badger'}

These positive framings of badgers could be regarded as culturally dominant: they would be recognisable to most British people, and as explored later in the article, the 'good badger' is certainly more prominent in popular culture. However, within the press coverage of badger/bTB, negative framings of badgers also appear, and perhaps surprisingly, they considerably outnumber references to the 'good badger'. Most obviously these badgers spread disease by transmitting bTB to domestic cattle, and potentially to humans:

\section{BADGER THE GOVERNMENT}

Until it was brought under control in the 1960s, TB was a serious danger in Britain. So there is cause for concern that, in the past decade, cases of this disease in cattle have soared. An expanding badger population is blamed. These animals carry TB though they themselves appear unaffected by it. One mouthful of grass on which a diseased badger has urinated is believed to carry sufficient tubercle bacilli to infect a cow. The worry is that humans could contract the illness through consuming unpasteurised milk products. (The Times 1999, May5) 
In contrast to the 'good badger' framing, 'bad badgers' are more often discussed in the plural, and in a depersonalised way. This plays into discussion of links between rising badger populations and the spread of bTB (Veterinary Association for Wildlife Management, 2010). In turn, this forms part of a complex of characteristics depicting badgers as an undesirable underclass: violent, disruptive, criminal and far too numerous.

\title{
INSIDE STORY: WHAT HAVE I DONE TO DESERVE THIS?
}

In the book [WiTW], Badger is a solitary creature. Round here, he'll be shacked up with a dozen friends and family. And quite likely, he'll have tuberculosis. (Perkins 1999, Apr 12; The Guardian, p. 8)

\section{SUPER FURRY ANIMALOR CATTLE-KILLING, TB-RIDDEN VERMIN?}

As the badger population has grown, they are increasingly in our back yards; as Colin Gray points out, just as we had urban foxes, increasingly we will be seeing urban badgers as they travel further in search of food. In some places this is already a reality. In Evesham last year, 'a rogue badger attacked five people during a 48-hour rampage in a quiet suburb'. In one suburb in Sheffield, it was recently reported, residents 'were demanding an $A S B O$ for sex-mad badgers'. There were 19 setts in a hundred yards of back gardens. Michael Broom- head, 60, a retired butcher, said: 'They have felled three trees by digging under them. When they are having sex they howl and scream, and when they are fighting they make terrible bloodcurdling noises as if they are being murdered'. (Adams 2008, May 4; Observer Magazine, p. 24)

While violence, or the capacity for it while being attacked, is part of the 'good badger' framing, the 'bad badger's predatory and violent behaviour is further emphasised:

\begin{abstract}
CULL OR CURE DILEMMA AS BADGERS GET BLAME FOR EPIDEMIC
Ground-nesting birds have also suffered in the explosion of badger numbers, according to Mr. Barker [a dairy farmer]. He believes there could be up to 50 badgers in the main sett alone. "I now have no lapwings, curlews or wild pheasants because there are so many badgers searching for food and taking all the eggs in the spring'. (Goodwin 1997, Dec 1; The Independent, p. 20)
\end{abstract}

There are several other aspects of badger behaviour emphasised in the 
'bad badger' framing, such as crop destruction and digging in particular. Badgers live under- ground in and continually dig: such activities can bring them into conflict with humans at times (Roper 2010, pp. 267-298).

\title{
THOUSANDS OF BADGERS ARE CONDEMNED TO DIE OVER TB FEARS
}

Farmers detest the nocturnal mammals not only because of the belief that they spread TB but because they flatten cereal crops, nibble growing corn on the cob, and even strip vineyards of grapes. (Hinsliff 1998, Aug 18; Daily Mail, p. 21)

\section{THE SMART SETT}

Aberdeenshire council is spending $£ 30,000$ on a new council home for a family of badgers because their present sett has undermined a main road between Huntly and Banff. (Daily Telegraph2001, Mar21; p. 25)

In the 'bad badger' framing, these features come together to depict an agent of chaos - and, due to legal protections, one which can escape 'justice':

\begin{abstract}
A VERMINOUS VIETCONG STALKSTHE COUNTRYSIDE
Not since the Beast of Bodmin, not since the Hound of the Baskervilles, had so awful a creature plagued the countryside. Meles vulgaris, something between a weasel and a bear, was overrunning hill and dale. And it was, of course, Labour's fault. What were the teddy- hugging, town-dwelling, pizzaeating classes going to do about it, I was asked? They would not be content until every rustic parlour was a zoo of free-range foxes, badgers, stags, kites and predatory geese? I could not argue the damage. Across the landscape meadows were being upheaved, hedges, banks and bridleways subsiding, tennis courts falling into holes. Tunnels of Ho Chi Minh ingenuity were sapping the ancient walls and lawns of England with a verminous Vietcong. These omnivorous monsters were eating lambs and groundnesting birds. They were the only known predator of the hedgehog. Archaeological sites werebeing destroyed. The killer brock was prowling at will, cockily secure under the 1992 Protection of Badgers Act. (Jenkins 2004, Apr 4; The Times, p. 24)
\end{abstract}

While this piece, in common with much newspaper commentary, is clearly written with humorous intent, it still expresses a common frustration with the legal protection of badgers in the UK. It also illustrates how controversies over badger culling are intertwined with tensions 
between traditional British rural centres of power and modern urban elites - at the time epitomised by successive Labour administrations. During their time in power (from 1997-2010), as well as gradually withdrawing licences for farmers to cull badgers, and ruling out a culling policy in 2008, the Labour government also outlawed foxhunting (Woods 2008). While the specifics of 'hunting' practices and controversies are distinct to those surrounding badger culling and baiting/digging (Marvin 2000), common intersections of power and political interests result in their alignment (e.g. May 2010).

The 'good' and 'bad' badger framings are clearly employed strategically by media and other actors engaged in arguments for and against culling policies. However, as is suggested by some of the examples above, each trope is also employed, albeit in an exaggerated form by the 'other' side as well, for example when pro-cull actors cite Wind in the Willows as the source of popular resistance to culling. Indeed, in some longer articles, authors switch rapidly between the two tropes, using them as a linguistic resource to explore the issue at depth. Grant (2009) and Enticott (2011a) also identify the use of good/bad badger tropes as linguistic resources, respectively by policymakers during the 1960s and 1970s; and farmers currently affected by bTB carrying out illegal culling. However, these take a distinctly different form, involving the attribution of bTB infection/spread to specific individuals: sick 'rogue badgers' whose behaviour is abnormal in many ways and must be 'taken care of' (Enticott 2011a; 204). This was not present in the media coverage of badger/bTB, although the related idea of expressing concern for the suffering of sick badgers was employed as part of pro-cull rhetoric:

\section{ANIMAL LOBBY CONDEMNS BADGERS TO SLOWDEATH \\ It [bTB] is also causing great suffering to the badgers themselves. Thousands die each week from the long-drawn-out effects of the disease (unless, as any West Country roadside bears witness, they are so weakened that they fall victim to a passing vehicle). (Brooker 2005, Mar 7; The Daily Telegraph, $p$ 14)}

This illustrates the flexibility of good/bad badger discourses, and the ways in which they can be taken up and strategically reshaped to suit changing contexts and audiences. 


\section{Framings of badgers before bovine TB}

As alluded to earlier, epidemiological links between bTB in domestic cattle and wild badger populations were not made until 1971, when a dead badger was found on a farm in Gloucestershire undergoing an anomalous outbreak of bTB (Muirhead and Burns 1974). But what led the vets investigating the case to make the connection; and then Government to implement a culling policy by 1975? (Grant 2009) While such a question cannot really be answered without a fuller historical investigation of this period, a brief examination of the electronic archive of The Times (17851985), offers some intriguing suggestions, at least in terms of media constructions of badgers before bTB. The earliest references to badgers occur as part of The Times' routine sports reporting:

\section{EASTER MONDAY SPORTS}

The first symptoms of sporting amusement that caught our observation appeared in the neighbourhood of Hampstead and Kentish-town. [...] the sportsmen of Kentish-town had assembled at the Bull and Gate, to prepare for a badger hunt; and fortified by their morning draughts, they set out for the field, not with 'Deep-mouthed hounds, and mellow toned horn', but keen scented terriers, and high-bred bulldogs, to assail the grizzly savage in his den, situationed in a field between Highgate and Hampstead. (The Times 1811, Apr16; The Times Archive, p. 3, issue 8271; col C)

Discussions of badgers as participants in apparently routine and popular sport hunting and digging activities continue as late as 1911, after which coverage of these activities shifts towards a more modern mode of disapproval.

It is not until 1877 that more positive framings of badgers start to appear, in the first of several sets of exchanges on the letters page of the newspaper.

\section{'THE BADGER' (LETTERS TO THE EDITOR)}

On fine evenings we can watch them dress their fur-like coats, or do kind office for each other, and search for parasites after the manner of monkeys. No creature is more cleanly in its habits. [...] they scrape their feet in dirty weather, and keep their house inodorous by depositing their excrement at one place for many months and covering it with earth. (Ellis 1877, Oct 24; The Times Archive, p. 5, issue 29081; col E) 
As in the contemporary coverage, this depiction of a clean, gentle, civilised animal was met (in a subsequent letter) with an opposed framing of a predatory animal which makes a nuisance of itself.

\begin{abstract}
'BADGERS' (LETTERS TO THE EDITOR)
That badgers dig out and eat young rabbits is a fact that can be documented beyond doubt in this district during the summer months to anyone who is incredulous on the subject. [...] In the early part of this year I was told by a farmer - whose veracity I have no reason to doubt - that he had been so annoyed by badgers treading down his crops in passing from one earth to another that he determined to dig them out, so that he could trap them. (Barnes 1877, Nov 17; The Times Archive, p. 4, issue 29102, col F)
\end{abstract}

Similar exchanges, often between amateur (and later professional) natural historians and farmers or landowners, also occurred during 1913, 1932 and 1941. These exchanges also present strikingly opposed 'good badger' and 'bad badger' framings. As well as the above emphasis on cleanliness and sociability, early twentieth century 'good badgers' were seen as brave, strong, ancient, family oriented, and somehow British in character.

\title{
'MEN AND BADGERS' (EDITORIAL)
}

The badger's kin may have lived in that spot centuries before there were any human beings there. Like the best people of ancient breeding, they had kept themselves to themselves, hiding by day, coming inoffensively out by night, resisting only - and then to the death - the attempts of the upstarts and interlopers to make of them either sport or shavingbrushes. (The Times 1927, Apr 28; The Times Archive, p. 15, 144567, colE)

It is worth noting however, that some features were distinctly different: 'good badgers' were lauded for eating rabbits, wasps nests, small rodents and nuisance insects, so making themselves useful to people. They were also considered to make excellent pets - all 'positive' features with a distinctly more utilitarian tone than the modern coverage.

The 'bad badger' was considered to be a nuisance due to its habits of digging and crop destruction, but was also accused of taking groundnesting birds, chickens and even young lambs. At this time, badgers were also considered to be a problem due to their perceived interference with foxes and foxhunting: 


\section{'THE BADGER: DAMAGE CAUSED IN THE HUNTING COUNTRIES' (LETTERS TO THE EDITOR) \\ In a hunting country, besides adding largely to the poultry claims, he does great damage by opening earths which have already been stopped. He will take possession of foxes earths and evict the rightful owners, in many cases driving them out of the coverts with which those earths are situationed. (Lascelles 1932, Aug 31; The Times Archive, p. 6, 146226; col B)}

Over time, negative framings of badgers became less and less frequent, and the animal was rarely mentioned in The Times until the mid1960s, when campaigns to extend legal protections got into full swing. Shortly after the passing of the Badger Act in 1973, the UK Government initiated culling for bTB control, and The Times' coverage shows that this policy was deeply controversial from the start. While this analysis can only really scratch the surface, there do seem to be some striking commonalities between media framings of badgers in the contemporary badger/bTB controversy, and how the animals were discussed during the late 19th and early 20th centuries. In order to give some much-needed context to these framings, we must move beyond the media to address the role of the badger in British society and culture more broadly.

\section{Badgers in British Culture}

As communications studies professor Julie Corbett (2006; ch. 7) has argued, our language and popular culture is saturated with representations of animals: as such any discussion of animals in media needs to take account of this broader context. While this paper cannot provide an exhaustive survey of 'badgers in popular culture' it will attempt to cover those key features relevant to the analysis so far. It is clear from the above contemporary and historical media coverage that the defining feature of the badger's role in popular culture is as an animal that was widely, and is now rarely, on the wrong end of a violent human-animal relationship. As the Times Archive material suggests, badger-baiting, digging and hunting were traditional and popular sports until relatively recently. 'Baiting' of badgers and other animals was made illegal in the UK in 1835. However, the related practice of 'digging' for badgers continued to be more or less legal until the Badger Act was passed in 1973. Further legislation followed in 1991 and 1992, making it a serious offence to 'kill, injure or take a badger', or to 'damage or interfere with a sett' without a licence. 


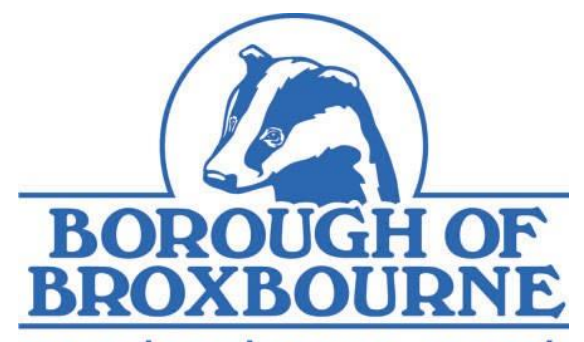

www.broxbourne.gov.uk

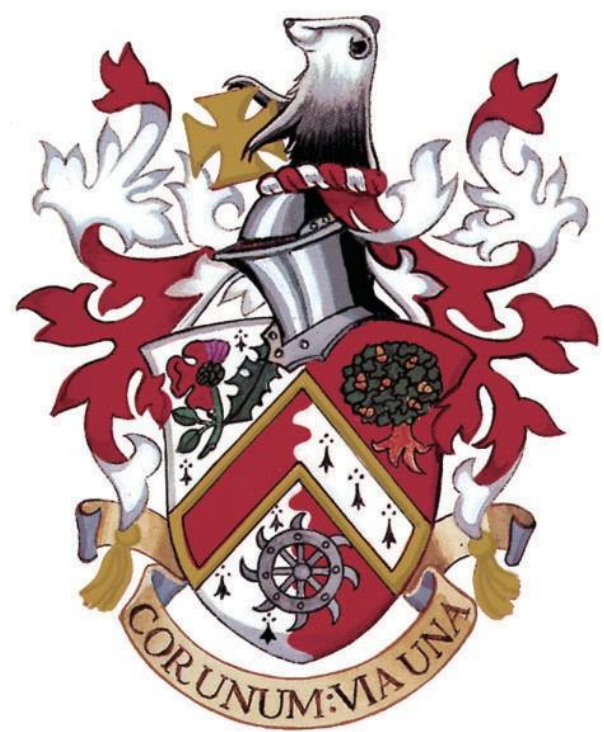

Figure 1: Traditional coat of arms and modern corporate logo of the UK Borough of Broxbourne (reproduced with kind permission of Broxbourne Borough Council).

Badgers were designated under the Tudor Vermin Acts of 1532 and 1566, which listed those animals the Crown believed to interfere with human activity, and offered financial rewards for their bodies. In this listing, badgers fetched a generous bounty of 12 old pence per head: a high price only shared by one other animal - the fox. In his study of churchwardens' records of these bounties, Roger Lovegrove (2007) intrigu- ingly reports that despite this high reward, relatively few badgers were killed under this and later systems of vermin control. Traditionally, badgers were also eaten, and parts of their bodies were utilised (e.g. in magical charms; hair for shaving brushes; and badger fat as a liniment) (Hardy 1975; Lovegrove 2007). At least some of these practices continue in parts of continental Europe today (Griffiths and Thomas 1997; Roper 2010, p. 33). The contemporary image of the badger as an animal rooted in a sense of place can indeed be read in in many place names across the UK, reflecting a long history of interaction with people in this country. Badgers also occasionally appear in heraldry: in local coats of arms (Fig. $1)$; in the fictional heraldry of House Hufflepuff of J.K. Rowling's Harry Potter books (e.g. Rowling 1997); and in 'heraldic' commercial imagery such 
as that employed by the Dorset based Hall and Woodhouse brewery chain (brewers of Badger beer).

Fictional badgers play an important role in the framing of the modern badger/bTB debate, providing journalists with easily recognisable 'hooks' from which a highly complex issue can be discussed. Of these 'Mr. Badger' from Kenneth Grahame's 1908 novel The Wind in the Willows (Grahame 1908) (WiTW) is the most frequently referenced example. Grahame's novel centres on four animal characters - the Mole, the Water Rat, Mr. Toad and Mr. Badger. Mr. Badger acts very much as a father figure to the others, but is also quite antisocial, intelligent and wise, and fearsome to friends and enemies alike. Grahame's book is a classic of British children's fiction: as well as undergoing multiple reprints, it has been adapted for the stage, radio and television many times. Visual representations of Mr. Badger have changed over the century since the book was first published. The earliest illustrated edition of the book, pub- lished in 1913, shows Badger and the other animals in a naturalistic style, unclothed (Grahame and Branscombe 1913): however it is the more humanised illustrations of E.H. Shepard (Grahame and Shepard 1931), evoked in the PrivateEyecartoon in Fig. 2, which have been most influential. This then shifts to the stern, grandfatherly, spectacle wearing character voiced by Michael Horden in the 1980s television adaptation (Hall and Cosgrove 1984-1987); and finally to the cover of the current Walker Illustrated Classics edition, showing the other animals gathered around Badger in a wing-chair in storytelling mode (Grahame and Moore 2009). 

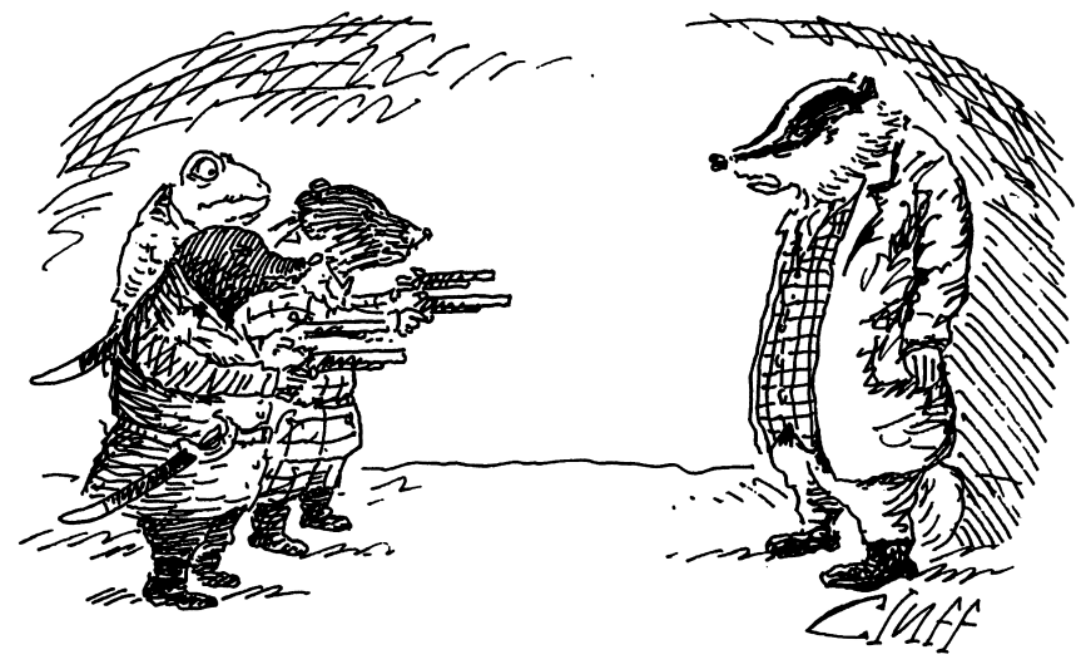

"It's nothing personal, Badger, it's just that we've been paid to cull you"

Figure 2: PrivateEye, issue1272,140ctober2010,p.18 (reproduced with kind permission of PRIVATE EYE magazine/John Longstaff).

These characteristics can be traced through a whole series of fictional badgers, both before and after WiTW, Indeed, they can be traced back as far as an Anglo-Saxon riddle poem, 'The Badger', ${ }^{6}$ dating back to the tenth century, which conjures imagery of an animal that lives in a hill, fighting and defending his family against digging invaders (Nelson 1975). The theme was picked up by the British romantic poet John Clare during the early nineteenth century. In his vividly written 'Badger' - written from the point of view of the animal being baited (Clare 1990); ${ }^{7}$ and reprised by the nature and war poet Edward Thomas in The Combe (Thomas 1917). A more academic, less heroic version of Mr. Badger appears in T.H. White's The Sword in the Stone (White1938), a children's novel about the young King Arthur, while more martial versions can be seen in CS Lewis's Prince Caspian (Lewis 1951), and fantasy author Brian Jacques' Redwall series (1986-2010; e.g. Jacques 1988), Colin Dann's Animals of Farthing Wood series (1979-1994; e.g. Dann 1979) reinterprets the character with a more explicitly environmental angle: Badger becomes a leader of a group of animals evicted from their home woodland by a housing development. Many of these sources share common themes, reflecting on human relationships with the natural environment, in specifically British (or English) contexts. 


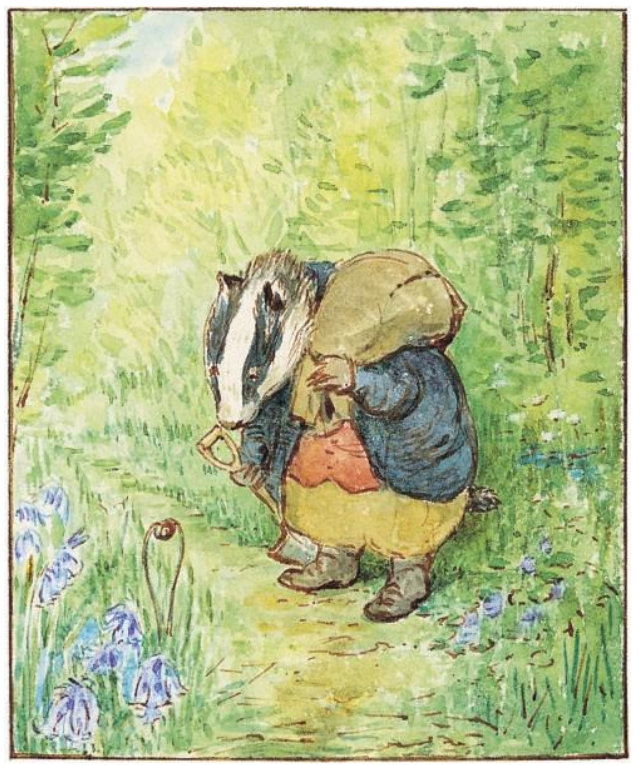

Figure 3: 'Tommy Brock', illustration from The Tale of Mr Tod by Beatrix Potter (1912, p. 21), (Copyright @ Frederick Warne \& Co. 1912, 2002; reproduced with permission of Frederick Warne \& Co.)

These provide a stark contrast to one of the few negative fictional portrayals of badgers: Beatrix Potter's The Tale of Mr. Tod (Potter 1912). Like Kenneth Grahame, Potter wrote children's books featuring humanised (British) animals: unlike Grahame, her work was explicitly aimed at teaching children something of natural history and animal behaviour. ${ }^{8}$ To modern eyes, The Tale of Mr. Tod is a grim tale about predation: the badger, Tommy Brock, uses guile to kidnap a nest of baby rabbits, who are then in turn stolen by the fox, Mr. Tod. The two fight, and in the confusion the babies' relatives manage to rescue them. Tommy Brock is a deeply unpleasant character, who as well as being sly and predatory is smelly, dirty, uncouth, and carries a spade (much like baiters and diggers), as seen in Fig. 3. He is also clearly cast as of the working/labouring classes, particularly in contrast to the 'gentleman' Mr. Tod, the fox. 
From the mid twentieth century onwards, badgers have also played a significant role in popular natural history and zoology. Ernest Neal's The Badger (Neal 1948) was a major scientific monograph, but also an exceptionally popular natural history book of the postwar period. It stayed in print until 1977, and was republished as a mass print Pelican paperback in 1958. Neal, a schoolmaster, was also a pioneer of nature photography, capturing early colour and video film of wild badgers. ${ }^{9}$ Through this work, he was closely involved in the early incarnations of the BBC Natural History Unit (Neal 1994; Marren 1995), and via this work played a significant role in the mutual constitution of wildlife documentary and the sciences of animal behaviour (Davies 2000). The Badger is a compelling combination of scientific monograph, firsthand narrative, and 'how to' manual for the aspiring amateur natural historian, clearly explaining how to conduct your own 'badger watch' if you should so wish. It describes badgers as clever, sociable, clean, civilised, and family oriented animals: terms immediately familiar from 'good badger' media framings.

In more recent popular cultural contexts, badgers have increasingly become increasingly abstracted forms: they often appear as part of a revolving cast of what Tess Cosslett describes as 'human beings with animal heads' (Cosslett 2006, p. 181) in children's TV and books: essentially stories about humans (usually children) who act as humans, but just happen to be depicted as animals. Particularly since the 1990s, this tendency towards abstraction has accelerated into surrealism and comedy, with even the word 'badger' being seen as simply funny, featuring in wordplay and stand-up comedy routines. ${ }^{10}$ Badgers even have their own Internet craze: the Badger-BadgerBadger animation, which simply involves animated badgers doing star jumps, followed by a mushroom and a snake, to the accompaniment of a catchy tune (Picking 2003). It is clear that in these contexts the badger's strikingly striped, monochrome face plays an important role. Indeed, visual representations of badgers often appear: from coats of arms through commercial and campaign logos, book illustrations, nature photography and documentary, visual arts, television programmes, and of course countless soft toys. The face lends itself to abstraction, and its image is often adopted beyond badger-specific issues into broader environmental and conservation campaigning, as can be seen in Fig $4 .{ }^{11}$ 


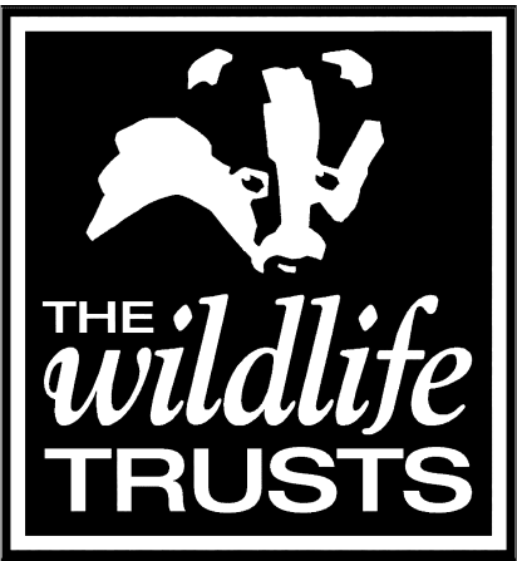

Figure 4: Logo of the UK Wildlife Trusts. (reproduced with kind permission of the Wildlife Trusts)

\section{Discussion}

This paper has offered an analysis of the modern badger/bTB controversy in the UK, looking at the strategic framing of badgers in arguments for and against proposals to cull them. Two opposing images appear: the 'good badger' and the 'bad badger', which are broadly, but not exclusively associated with arguments for and again culling policies. Media framings of badgers prior to their association with bovine TB have been discussed, highlighting some striking continuities over the past two centuries. Due to the prominence of cultural references to badgers in contemporary media coverage, these have also been discussed at some depth, looking at how the animal has been portrayed in British fiction, poetry, popular natural history, contemporary comedy and visual iconography. Through these sources, the roots of several versions of the 'good badger' have been traced, as well as highlighting a rare but significant representation of the 'bad badger'.

This analysis suggests that badgers have occupied an intensely ambivalent position in British society since at least the mid nineteenth century, although it is far from a comprehensive historical investigation of the issue. Various aspects of badger behaviour bring these animals into conflict with humans: on the other hand they have a range of other characteristics which people have found admirable and aesthetically 
pleasing. Some of these, such as strength, bravery and loyalty to family, are features which may be displayed during baiting and digging activities: this valorisation of and sense of closeness to the 'hunted' animal by the 'hunter' is not unusual (Marvin 2000; Carvalhedo Reis 2009). Through longstanding British artistic traditions inspired by nature and the countryside, as well as in more recent traditions of popular natural history, badgers are widely regarded as a 'charismatic animal' in the UK (Lorimer 2007). Such animals are often used to bring attention to conservation campaigning: the fact that badgers are used in this way while being so common fits with such a 'charismatic' status, and may go some way towards explaining the strength of opposition to badger culling in the UK (Bennett and Willis 2008; Defra 2011).

Many of the descriptions of 'bad badgers' are also congruent with more general features of language about animals are in conflict with humans and ascribed to the category 'pest' or 'vermin'. Knight's (2000b) framework of 'pestilence discourses', in which such animals are represented as dirty, violent, criminal, cunning, highly numerous and out of control, and their harmful effects upon humans are exaggerated, neatly describes many of the features of the 'bad badger' seen here. ${ }^{12}$ Knight and his colleagues highlight the dualistic nature of these discourses, and again this is very much in evidence in the material presented here. These dualistic framings of badgers invoke important notions of space, and the proper occupation of space, by humans and other animals. The 'good badger' is often seen as symbolic of an idealised British nature or countryside, and as such is often constructed as occupying 'natural', nonhuman spaces such as Kenneth Grahame's 'Wild Wood'. In contrast, 'bad badgers' are invariably framed as intruders into human, albeit agricultural, space, where they disrupt and impede human activities (see also Spencer 2010). Animals which disrupt the boundaries (spatial or otherwise) constructed between humans and animals (and by implication humans and 'nature') are therefore more likely to be designated as pests: however because such a role is inherently ambiguous, constructions of such animals are also likely to flip between positive and negative according to context, particularly when broader environmental conflicts are involved (see also Jones 1999; Hytten 2009; Potts 2009).

The constructed nature of these characterisations is also highlighted by changes in their definition over time. This may have been important in 
the transition from debates about badgers to debates about badgers and bTB. The historian Mary Fissell (1999) argues that the category 'vermin' in early modern England was oriented around animals in direct competition with humans for resources, which would explain why vermin animals were (and are) frequently portrayed (and treated as) criminals - present even in the modern 'bad badger'. Fissell also identifies a clear discontinuity between 'vermin' of this period and their modern counterparts - a complete lack of association with dirt, disease and disgust. This suggests that such associations (Douglas 1966) may have developed alongside medical understandings of the causes and spread of disease: Fissel identifies that by the nineteenth century they were certainly in place. The contemporary connection between badgers and bovine TB is facilitated both by longstanding historical framings of badgers as vermin, and by modern understandings of vermin/pests as associated with dirt and disease transmission. Recent literature on rhetorical and social aspects of disease risks would support such an assertion. Research by Brigitte Nerlich and colleagues has high- lighted common discourses of 'waging war', 'apocalypse', the enclosure of space (biosecurity) and attributions of risk outside such spaces across foot and mouth disease, pandemic flu, 'superbugs' and other contemporary disease threats (Lien and Nerlich 2004; Nerlich et al. 2009; Nerlich and James 2009), many of which have been referenced in debates over bTB.

Similarly, Joffe (1999) has argued that societies often handle disease risks by 'othering' and excluding particular groups or individuals as the source of disease, as was seen with gay men during the early HIV/AIDS crisis. In a recent paper, Joffe analyses public responses to the risks of pandemic flu, and suggests that because the risks in this case have been attenuated, there has been a corresponding lack of 'othering' (Joffe 2011). However, Joffe only includes humans in her analysis, and if nonhumans are included, it becomes rapidly clear that much of the anxiety has instead been transferred to animals, in the form of 'bird' and 'swine' flu. Indeed, Gerber et al. (2011) chart an escalation in narratives of risk around animals in the Swiss media, including avian flu, dog attacks and food poisoning. They attribute this escalation in part to broader transformations in human relationships with 'nature' and the environment, disrupting societal boundaries drawn between the two. 
By comparing contemporary public debates over badgers and bTB with older media and cultural representations of badgers, a tentative historical narrative can be traced in relationships between humans and badgers in the UK. From an early period in which badgers were commonly considered to be vermin (albeit occasionally admired), this moved towards the gradual appearance of the 'good badger' during the nineteenth and early twentieth century. During this period, the emergence of early animal welfare movements and resulting changes in social attitudes gradually marginalised, and eventually outlawed common interactions with badgers via baiting and digging. The first two decades of the twentieth century seem to have provided something of a turning point, after which positive constructions of badgers have become increasingly culturally dominant, reifying themselves into increasingly abstracted forms. The contemporary controversy over badgers and bTB can therefore be read as a continuation of this longstanding 'badger debate' about the appropriate position of these animals in British society: as pests to be 'managed' and removed when they get in our way; or a cherished, charismatic wildlife species to be preserved. It seems that current associations between disease, risk and animals (particularly pests) have therefore contributed to the reemergence of the 'bad badger' into public discourse. ${ }^{13}$ Considering the omnipresence of war and apocalypse metaphors in media coverage of disease more generally, the reversal of these into anti-war rhetoric by anti-cull actors is intriguing, and is suggestive of appeals to specific, rather than general public audiences.

These findings have two key implications for the badger/bTB controversy itself. Firstly, there is a pressing need to reframe public debates beyond the reductive yes/no question of badger culling, and to 'open up' (Stirling 2008) broader questions sur- rounding the underlying problem of bTB spread, its potential causes and solutions. A key first step towards this would be to acknowledge the existence of an underlying 'badger debate' (about living alongside badgers), and take steps to address problems of human/badger conflict that are not about bTB. Secondly, there is a need to inves- tigate relationships between these dichotomous representations of badgers, and changing societal structures, publics' attitudes, human practices and local ecologies. This can help point us towards better understanding and potential resolutions of this protracted and divisive controversy, which has yet to find a satisfactory solution for any of the humans or other animals involved. 


\section{Notes}

1 See Caplan (2010) for a short but useful summary of the situation in Wales.

2 See Horton (2008a, 2008b) for a similar approach to the collection and analysis of a mix of media, cultural and interview data, which has in part inspired this study.

3 Many local Wildlife Trusts, alongside landowners and farmers, now conduct supervised or unsupervised 'badgerwatching' on a routine and frequently commercial basis: see, e.g. http://www.badger.org.uk/content/Living.asp for listings; and http://www.badgerwatch.com/ for a lay perspective on the practice.

4 This contrasts with the notorious difficulties of 'seeing' or indeed studying many wild animals (Rees 2006). It does seem that the relative visibility of birds plays an important role in the popularity of birdwatching as a leisure activity (see Law and Lynch 1988; Moss 2004; Cammack etal. 2011).

5 I generally avoid the term 'anthropomorphic', as it seems too normatively loaded to be helpful in understanding how and why people tend to highlight the similarities between themselves and other animals in this way.

6 The nature of the poem is such that the animal is never identified, but it has popularly been considered to be a badger: for arguments to the contrary, see Bitterli (2007).

7 Alongside other Romantic poets, Clare's work expressed and was important in shaping the incipient animal rights movement in Britain: see Perkins (2003) for a more in-depth discussion.

8 For a useful comparison of the differences, similarities and varying aims of Grahame and Potter's work, see Cosslett (2006).

9 The cover of Neal's autobiography (Neal 1994) references this work and the cultural role of the badger by depicting the animal in schoolmaster's robes.

10 See, e.g. material by the British comedians Eddie Izzard, Marcus Brigstocke and Harry Hill.

11 I understand that part of the reason for the adoption of the badger face as the logo for the UK Wildlife Trusts is that the simple monochrome image can be easily copied using the scarce resources available to NGO campaigners (O. Jones, pers. comm.); see also Nicholls (2011) for the role of abstraction in conservation logos.

12 There are intriguing parallels between such discourses about pests, and those surrounding marginalised groups of humans, see, e.g. Marcu et al. (2007).

13 While it is far beyond the scope of this article to draw any links between this reemergence and changes in human attitudes or practices towards badgers, Enticott's (2011b) paper does suggest that the severity of the bTB problem, and farmers' lack of ability to take action, is leading to (illegal) private practices of badger culling.

\section{Acknowledgements}

The research leading to this article was carried out with the support of an Interdisciplinary Early Career Fellowship from the Rural Economy and Land Use Programme (grant no. RES229-27- 0007-A). I would like to acknowledge the contribution of Dr. Charlotte Kenten to the early stages of this research, and thank the various mentors for the Fellowship for their feedback and support in developing this research. Finally, I would like to extend my thanks to the article referees, whose insightful and helpful comments have contributed greatly to the quality of this piece. 


\section{References}

Adams, T. (2008) Super furry animal or cattle-killing, TB-ridden vermin? Tim Adams on the problem with badgers. ObserverMagazine, May 4, p. 24

Allen, D. (2010) Otter (London: Reaktion Books)

Askwith, J. (2003) If you go down to the woods today; to some, they're charming, gentle creatures. To others, they're a menace. The Independent, Jun 13

Barnes, G. (1877) 'Badgers' (Letters to the editor). The Times Archive, Nov 17, p. 4, is 29102, col F

Barnes, J. (2006) Stop picking on Mr. Brock: it's the silly cow with TB you should be blaming. The Times, Oct 7, p. 23

Beardsall, J. (2003) Black and white and bred all over Thanks to dairy farming, badgers are thriving in areas such as Somerset, says Jonny Beardsall. Daily Telegraph, Aug 9, p. 12

Bennett, R.M. and K.G. Willis (2008) Public values for badgers, bovine TB reduction and management strategies. Journal of Environmental Planning and Management 51 (2) pp. $511-523$

Bitterli, D. (2007) Exeter book riddle 15: some points for the porcupine. AngliaZeitschrift Für Englische Philologie 120 (4) pp. 461-487

Brooker, C. (2005) Animal lobby condemns badgers to slow death. TB epidemic notebook. The Daily Telegraph, Mar 7, p. 14

Byrne, A., D.P. Sleeman, J. O'Keeffe and J. Davenport (forthcoming) The ecology of the Eurasian Badger (Meles meles) in Ireland: a review. Biology and EnvironmentProceedings of the Royallrish Academy DOI: 103318/BIOE.2012.02 Accessed 4 March 2012

Cammack, P.J., I. Convery and H. Prince (2011) Gardens and birdwatching: recreation, environmental management and human-nature interaction in an everyday location. Area 43 pp. 314-319

Caplan, P. (2010) Death on the farm: culling badgers in North Pembrokeshire. Anthropology Today 26 (2) pp. 14-18

Carvalhedo Reis, A. (2009) More than the kill: hunters' relationships with landscape and prey. Current Issues in Tourism 12 (5) pp. 573-587

Clare, J. (1990) John Clare: selected poems (London: Penguin)

Corbett, J.B. (2006) Communicating nature: how we create and understand environmental messages (London: Island Press)

Cosslett, T. (2006) Talking animals in British children's fiction, 1786-1914 (Aldershot: Ashgate Publishing)

Daily Telegraph (2001) The smart sett. Daily Telegraph, Mar 31, p. 25

Dann, C. (1979) The Animals of Farthing Wood(London: Egmont Publishing)

Davies, G. (2000) Science, observation and entertainment: competing visions of postwar British natural history television, 1946-1967. Cultural Geographies 7 (4) pp. 432-460

Defra (2010) Bovine tuberculosis: the government's approach to tackling the 
disease and consultation on a badger control policy. Available online at http://www.defra.gov.uk/corporate/consult/tb-control-measures/100915-tbcontrol-measures-condoc.pdf

Defra (2011) Bovine tuberculosis: the government's approach to tackling the disease and consultation on a badger control policy summary of consultation responses. Available online at http://archive.defra.gov.uk/corporate/consult/tb-control-measures/bovinetbsummary-responses-110719.pdf

Douglas, M. (1966) Purity and danger: an analysis of concepts of pollution and taboo (London: Routledge \& Kegan Paul)

Ellis, A. (1877) 'The Badger' (Letters to the editor). The Times Archive, Oct 24, p. 5, iss 29081; col E

Ellis, S. (2002) Tea for two, please. The Times (Weekend), July 6, p. 6

Enticott, G. (2001) Calculating nature: the case of badgers, bovine tuberculosis and cattle. Journal of RuralStudies 17 (2) pp. 149-164

Enticott, G. (2008) The spaces of biosecurity: prescribing and negotiating solutions to bovine tuberculosis. Environment and Planning A 40 (7) pp. 1568-1582

Enticott, G. (2011a) Techniques of neutralising wildlife crime in rural England and Wales. Journal of Rural Studies 27 (2) pp. 200-208

Enticott, G. (2011b) The local universality of veterinary expertise and the geography of animal disease. Transactions of the Institute of British Geographers 47 (1) pp. $75-88$

Enticott, G., A. Donaldson, P. Lowe, M. Power, A. Proctor and K. Wilkinson (2011) The changing role of veterinary expertise in the food chain. Philosophical Transactions of the Royal Society B: Biological Sciences, 366 (1573) pp. 1955-1965

Fissell, M. (1999) Imagining vermin in early modern England. History Workshop Journal 47 (Spring) pp. 1-29

Gerber, D.L.J., C. Burton-Jeangros and A. Dubied (2011) Animals in the media: new boundaries of risk? Health, Risk \& Society 13 (1) pp. 17-30

Goodwin, S. (1997) Cull or cure dilemma as badgers get blame for epidemic. The Independent, Dec 1, p. 20

Grahame, K. (1908) The Wind in the Willows (London: Methuen)

Grahame, K. and P. Branscombe (1913) The Wind in the Willows (New York: C. Scribner's Sons) Retrieved from Project Gutenburg at:

http://www.gutenberg.org/files/27805/27805-h/27805-h.htm Accessed 1 September 2011

Grahame, K. and I. Moore (2009) The Wind in the Willows (London: Walker Books) Grahame, K. and E.H. Shepard (1931) The Wind in the Willows (London: Methuen) Grant, W. (2009) Intractable policy failure: the case of bovine TB and badgers.

The British Journal of Politics \& International Relations 11 (4) pp. 557-573

Griffiths, H.I. and D.H. Thomas (1997) The conservation and management of the European badger (Meles meles). Nature and Environment, No. 90 (Strasbourg: Council of Europe Publishing) 
Guardian Leader (2007) Leading article: in praise of ... Badgers. The Guardian, May 15, p. 28

Hall, M. and B. Cosgrove (1984-7) The wind in the willows (TV series) (Manchester: Cosgrove Hall Productions)

Haraway, D. (2007) When species meet (Minesota: University of Minnesota Press) Hardy, P. (1975) A lifetime of badgers (Newton Abbot [etc.]: David and Charles) Hattersley, R. (2005) A cull by royal appointment. The Times, Dec 22, p. 18 Hinsliff, G. (1998) Thousands of badgers are condemned to die over TB fears. Daily Mail, Aug 18, p. 21

Horton, J. (2008a) Producing Postman Pat: the popular cultural construction of idyllic rurality. Journal of Rural Studies 24 (4) pp. 389-398

Horton, J. (2008b) Postman Pat and me: everyday encounters with an icon of idyllic rurality. Journal of Rural Studies 24 (4) pp. 399-408

Hytten, K. (2009) Dingo dualisms: exploring the ambiguous identity of Australian dingoes. Australian Zoologist 35 (1) pp. 18-27 Independent Scientific Group on Cattle TB (2007) Final report of the Independent Scientific Group on Cattle TB (London: Department of the Environment and Rural Affairs) Available online at:

http://archive.defra.gov.uk/foodfarm/farmanimal/diseases/atoz/tb/isg/report/fina I report.pdf

Jacques, B. (1988) Mossflower (London: Hutchinson)

Jenkins, S. (2004) A verminous Vietcong stalks the countryside. The Times, Apr 4, p. 24

Joffe, H. (1999) Risk and the other (Cambridge: Cambridge University Press)

Joffe, H. (2011) Public apprehension of emerging infectious diseases: are changes afoot? Public Understanding of Science 20 pp. 446-460

Jones, S. (1999) Becoming a pest: prairie dog ecology and the human economy in the Euroamerican west. Environmental History 4 (4) pp. 531-552

Knight, J. ed. (2000a) Natural enemies: people-wildlife conflicts in anthropological perspective (London: Routledge)

Knight, J. (2000b) Introduction. pp. 1-36 in Natural enemies: people-wildlife conflicts in anthropological perspective (London: Routledge)

Krebs, J.R. and the Independent Scientific Review Group (1997) Bovine tuberculosisin cattle and badgers. Report to the Rt. Hon Dr. Jack Cunningham MP(London: MAFF Publications)

Lascelles, E. (1932) 'The Badger: damage caused in the hunting countries' letter from Edward Lascelles. The Times Archive, Aug 31, p. 6, I 46226; col B

Law, J. and M. Lynch (1988) Lists, field guides, and the descriptive organization of seeing: birdwatching as an exemplary observational activity. Human Studies 11 (2) pp. 271-303

Lester, L. (2010) Media and environment: conflict, politics and the news (Cambridge: Polity) Lewis, C.S. (1951) Prince Caspian: the return to Narnia (London: Geoffrey Bles) Lien, M. and B. Nerlich, eds (2004) The politics offood (London: Berg) 
Lorimer, J. (2007) Nonhuman charisma. Environment and Planning D: Society and Space 25

(5) pp. 911-932

Lorimer, J. (2010) Elephants as companion species: the lively biogeographies of Asian elephant conservation in Sri Lanka. Transactions of the Institute of British Geographers 35 pp. 491-506

Lovegrove, R. (2007) Silent Fields: the long decline of a nation's wildlife (Oxford; New York: Oxford University Press)

Marcu, A., E. Lyons and P. Hegarty (2007) Dilemmatic human-animal boundaries in $\mathrm{B}$ ritain and Romania: post-materialist and materialist dehumanization.

British Journal of Social Psychology 46 (4) pp. 875-893

Marren, P. (1995) The New Naturalists: half a century of British natural history (London: HarperCollins)

Marvin, G. (2000) The problem of foxes: legitimate and illegitimate killing in the English countryside. Pp. 189-211 in J. Knight ed., Naturalenemies: people-wildlife conflicts in anthropological perspective (London: Routledge)

Marvin, G. (2001) Cultured killers: creating and representing foxhounds. Society and Animals 9 pp. 273-292

May, B. (2010) Save me (campaign website) Available online at http://www.saveme.org.uk Accessed 14 October 2010

Mitchell, S. (2006) TB OR NOT TB? Badgers are on trial, accused of spreading tuberculosis. Before the jury is dismissed on Friday, Sandy Mitchell talks to both defence and prosecution. Daily Telegraph (Weekend), Mar 4, p. 1

Molloy, C. (2011) Popular media and animals (Basingstoke: Palgrave Macmillan)

More, S.J. (2009) What is needed to eradicate bovine tuberculosis successfully: an Irish perspective. Veterinary Journal 180 (3) pp. 275-278

Moss, S. (2004) A bird in the bush: a social history of birdwatching (London: Aurum)

Muirhead, R.H. and K.J. Burns (1974) Tuberculosis in wild badgers in Gloucestershire: epidemiology. Veterinary Record 95 (24) pp. 552-555

Neal, E. (1948) The badger [Collins New Naturalist Monograph, 1] (London: Collins)

Neal, E. (1994) The badger man: memoirs of a biologist (Ely: Providence Press)

Nelson, M. (1975) Old English riddle no. 15: 'The badger': an early example of mock heroic.

Neophilologus 59 (3) pp. 447-450

Nerlich, B., B. Brown and N. Wright (2009) The ins and outs of biosecurity: bird 'flu in East Anglia and the spatial representation of risk. Sociologia Ruralis 49 (4) pp. 344-359

Nerlich, B. and R. James (2009) 'The post-antibiotic apocalypse' and the 'war on superbugs': catastrophe discourse in microbiology, its rhetorical form and political function. Public Understanding of Science 18 pp. 574-590

Nicholls, H. (2011) The art of conservation. Nature 472 (7343) pp. 287-289

O'Keefe, P.J. (2007) Introduction: hunting as heritage: Save a Whale, Harpoon a Makah?

InternationalJournal ofCultural Property14(03) pp. 279-282 
Perkins, A. (1999) Inside story: what have I done to deserve this? The Government is about to launch a badger-culling campaign. But instead of solving a problem, it's likely to cause a new catastrophe in the countryside, says Anne Perkins. The Guardian, Apr 12, p. 8

Perkins, D. (2003) Romanticism and animal rights (Cambridge studies in Romanticism) (Cambridge; New York: Cambridge University Press)

Philo, C. and C. Wilbert (2001) Animal spaces, beastly places: new geographies of human-animal relations (London: Routledge)

Picking, J. (2003) Badger badger badger. [Web animation] Available online at: http://weebls-stuff.com/songs/badgers/ Accessed 1 September 2011

Potter, B. (1912) The tale of Mr. Tod (London: Frederick Warne \& Co.) Retrieved from Project Gutenburg at: http://www.gutenberg.org/files/19805/19805h/19805h.htm Accessed 1 September 2011

Potts, A. (2009) Kiwis against possums: a critical analysis of anti-possum rhetoric in Aotearoa New Zealand. Society and Animals 17 pp. 1-20

Rees, A. (2006) A place that answers questions: primatological field sites and the making of authentic observations. Studies in the History and Philosophy of Science C 37 pp. 311-333

Roper, T.J. (2010) Badger (the new naturalist library) (London: Collins)

Rowling, J.K. (1997) Harry Potter and the Philosopher's Stone (London: Bloomsbury)

Ryan, T.J., P.G. Livingstone, D.S.L. Ramsey, G.W. de Lisle, G. Nugent, D.M. Collins and B.M. Buddle (2006) Advances in understanding disease epidemiology and implications for control and eradication of tuberculosis in livestock: the experience from New Zealand. Veterinary Microbiology 112 pp. 211-219

Spencer, A. (2011) One body of evidence, three different policies: bovine tuberculosis policy in Britain. Politics 31 (2) pp. 91-99

Spencer, M. (2010) Imagining badgers: an attempt at working with objects of governance. Conference paper circulated for Sentient Creatures: Transforming Biopolitics and Life Matters, University of Oslo, 16-17 September 2010

Stirling, A. (2008) Opening Up and Closing Down: power, participation and pluralism in the social appraisal of technology. Science Technology and Human Values 33 (2) pp. 262-294

Strauss, A. and J. Corbin (1998) Basics of qualitative research: techniques and procedures for developing grounded theory.2nd edn (Thousand Oaks, Calif.; London: Sage Publications)

Syse, K.V.L. (2010) Spot the Otter! Otters as mediating and unifying symbols in British society. Conference paper circulated for Sentient Creatures: Transforming Biopolitics and Life Matters, University of Oslo, 16-17 September 2010

The Times (1811) Easter Monday sports. The Times Archive, Apr 3, p. 3, iss 8271; col C The Times (1927) 'Men and badgers' (Editorial). The Times Archive, Apr 28, p. 15, I 44567, col E The Times (1999) Badger the government. The Times, May 5 Thomas, E. (1917) Poems (London: Selwyn \& Blount) Veterinary Association for Wildlife Management (2010) Badgers and Bovine TB Available 
online at:

http://www.vetwildlifemanagement.org.uk/index.php?option=com content\&task =view\&id=14\&/temid=28 Accessed 13 October 2010

Waddington, K. (2006) The Bovine Scourge: meat, tuberculosis and public health (Woodbridge:

The Boydell Press)

Weathers, H. (2003) Mother badgers are snared in rusty cages, parted from their screaming cubs and coldly shot in the head ... all with the Government's blessing. Daily Mail, June 3, p. 11

White, T.H. (1938) The Sword in the Stone (New York: G. P. Putnam's Sons)

Wilkinson, K. (2007) Evidence based policy and the politics of expertise: a case study of bovine TB. CREDiscussion Paper 12. [Working paper] Available online at: http://www.ncl.ac.uk/cre/publish/discussionpapers/pdfs/dp12\%20Wilkinson.pdf Accessed 5 March 2012

Woods, M. (2000) Fantastic Mr. Fox? Representing animals in the hunting debate. Pp. 183-202 in C. Philo and C. Wilbert eds, Animal spaces, beastly places: new geographies of human-animal interactions (London: Routledge)

Woods, M. (2008) Hunting: new labour success or new labour failure? Pp. 95-114 in M. Woods ed., New Labour's Countryside: rural policy in Britain since 1997 (Birmingham: The Policy Press) 